\title{
Formation of working environment and capacity of a management at the enterprise
}

\author{
Fedor Zotov \\ Associate professor, candidate's degree, associate professor, department of quality management, \\ USUE, Ekaterinburg
}

\begin{abstract}
The formation of a methodology of a supporting of a development of an enterprise management system is a direction of the author's research. As part of the study in this work, it seemed appropriate to present the author's point of view on understanding the place of management in a modern industrial enterprise. In management theory, interpretations of similarities and differences in the contents of the terms "management" and "administration" are found. In this work, a comparative analysis of the concepts of "management" and "business administration" is carried out. In determining these concepts, the functional content, essence and relationship of management and business administration in the enterprise are highlighted. Based on the analysis, the management potential is formed. Management aspects of the activity are identified as such potential. As a working environment for the implementation of management potential, flows are defined. The main flows constituting the activities of the enterprise are presented. A stream visualization tool, the Senkai diagram, was brought in. The visualization of the flows made it possible to identify the area of application of the management potential, both for solving the current practical problems of the business and for the development of the enterprise management system.

It is proposed to consider the results of the study as an approach to solving the urgent problem of streamlining an expensive managerial resource in the enterprise. The analysis of the achievements in solving this problem, published in domestic and foreign literature and related to overcoming the existing state in the management activities, is carried out. The causes of the problem are highlighted. An analysis of the reasons led to the conclusion that, within the framework of the existing approaches to management, the manager cannot carry out full-fledged effective activity. A generalization of the research results made it possible to identify the main directions for solving the problem. Mostly this decision is expressed in increasing the effectiveness of the actions of officials at different levels of the hierarchical structure, that is, in the chain of relations "leader - subordinate." In this study, the author proposed an approach to solving the problem, which consists in eliminating the overlapping responsibilities of managers at the hierarchical levels of the administrative structure. This approach involves the transformation of the structure.

Keywords: enterprise, business administration, management, flow, capacity, visualization, management method, management resource, streamlining.
\end{abstract}




\section{Introduction}

The topic of the interpretation of the essence and content of management is covered with the enough works, which are written by both domestic and foreign researchers. However, according to the author's opinion, the definitions and translations of the concept of "management", which are introduced in these works confuse an issue with the traditional terms "management", "leadership" and "administration", and keep this confusion at the present stage of the management development. For example, the widely used definition of the term "management", given in the latest standard ISO 9000 standard, is interpreted as "coordinated activities for the administration of the organization" [9].

The purpose of this work was to consider the established approaches towards management from the standpoint of the implementation of a full-fledged effective activity, and in particular, to consider the streamlining of expensive managerial resources in the enterprise's business. To achieve this goal, there were set 5 tasks, sequentially. At first, it was important to establish the understanding of the purpose, nature and content of management itself. Secondly, the task was to determine the management potential, which is ready for the implementation in the environment where the activities of the enterprise are expanding. The third task was to determine the working environment in which the management potential is realized. The fourth task was to provide an illustration of the work environment, to facilitate the management for the realization of its potential. The fifth and the last task was to create the assumptions for solving the problem of streamlining costly managerial resources in the structure of a modern industrial enterprise.

\section{Methods and materials}

Management is the subject of many sciences. For example, from a sociological point of view, management "is a hierarchical system of people's relations based on differences in official position, status, income and range of authority" [11]. From the point of view of the system approach, management is defined as "the targeted impact of one subsystem on another subsystem in order to change its behavior in a certain direction" [17].

A separate subject is the understanding of the term "management" as "governance" in various scientific and popular publications without any special explanation. Moreover, in the predominant number of interpretations of the term "management" there is the term " governance". A number of researchers drew attention to this problem. In particular, V.V. Okrepilov drew attention to the difference in the content of the terms "management", "governance" and "administration" in their practical application. [15].

This work does not provide a new interpretation of the term "management". However, the management potential and the working environment, in which it is proposed to realize above potential are represented. A stream is exposed as a working environment for management, which is understood as "a set of objects, which is perceived as a whole, existing as a process on a certain time interval and measured in absolute units over a certain period of time" [3].

The main parameters of the flow, most commonly, are the following: the start and the end points; trajectory; the path length; the speed and movement time; any intermediate points and the intensity. This paper gives examples of the graphic display of material, cash and informational flows. Material flow defines the flow of products (inventory), considered together with various logistic and / or technological processes and assigned to a certain time interval (Figure 1). Simultaneously with the material flow, if it is necessary, a service flow could be established. The purpose of management is to coordinate the flow to meet the requirements of the recipients. 
In a market economy, the increase of the efficiency of movement of goods flows and service flows is achieved mainly by improving their financial services, which, in turn, necessitates the allocation and study of financial flows. The financial flow is understood as the directional movement of funds, which are circulating in the economic system, as well as between the system and the external environment.

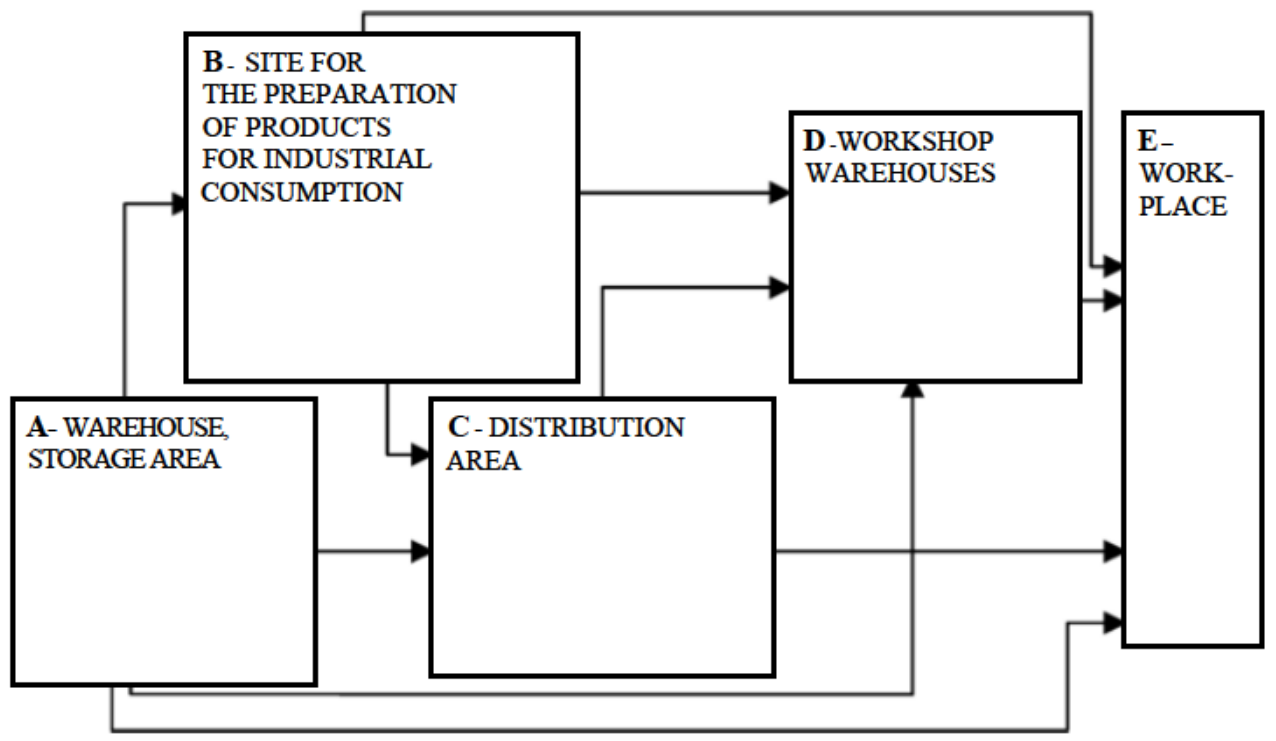

Fig. 1. Scheme of material flow at the stage of production support with material resources, compiled by the author.

It is proposed to define the informational flow as a message flow in speech, document (paper and electronic) and other forms generated by the original material flow and intended for implementation of control actions. Informational flows, which are accompanying certain operations, such as production procedures, transportation, order management, could be very complex and rich with workflow schemes, with the number of documents and their detalization.

To illustrate the flows in the activities of the enterprise, it seemed appropriate to use the Sankey diagram being the one of the effective ways to understand the structure of flows. The chart is named after its creator Matthew H. Sankey. The Sankey diagram reflects the intensity of the flow in each section, the load, throughput, relationships, the specific contribution of the private flow to the total flow. The diagram is widely used in energy management (Figure 2). However, this is not the only direction of management where flows can be illustrated. Moreover, it could be argued that in those business flows of the enterprise where the management potential begins to be realized, it is appropriate to use the Sankey diagram. 


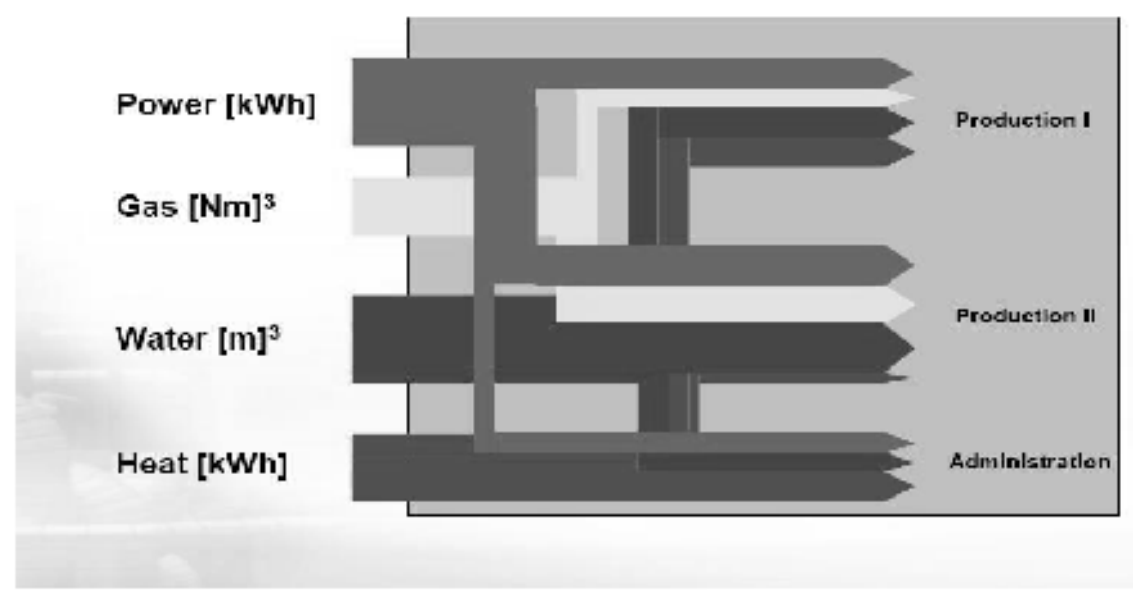

Fig. 2. Display of energy flow using the Sankey diagram, compiled by the author.

In particular, using the Sankey diagram it is possible to illustrate the cash flow in a financial stream (Figure 3). The financial condition of the enterprise depends on the implementation of the financial flow [7].

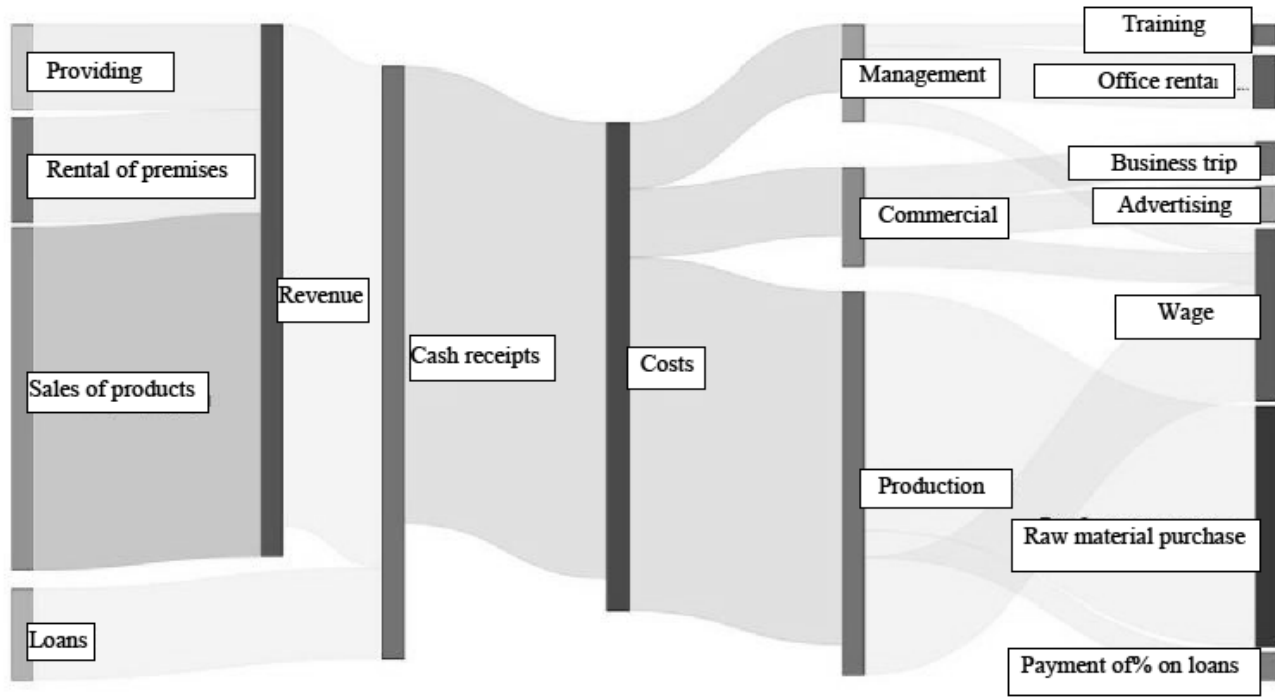

Fig. 3. Visualization of financial flows in the enterprise using the Sankey diagram [12].

The classic functions of the enterprise administration were described by Henri Fayol in his scientific studies as "5 components of administration" [18]. Let one understand these components as enterprise business administration (or business administration).

The business administration of the enterprise runs the business. The aim of the work is to ensure that the business is consistent with its objectives and is properly organized and coordinated. The business administration draws up plans for management and monitors the work of managers, ensuring their commitment to the policies of the enterprise and effective work to achieve the goals and objectives of the enterprise and the implementation of plans.

Traditionally, the business administration of the enterprise, within the framework of the established organizational structure, solves the tasks of resources' provision, making 
decisions, controlling and supervising business operations (projects, production, sales, logistics) together with related areas (finance, personnel, information technology, marketing).

The business administration devotes one of its administrative tasks to the formation of management areas. As a result of solving this problem, enterprises of various directions appear at the enterprise, for example, social, industrial, financial and informational.

Based on the scope of the enterprise, the business administration forms next flows: social (people), material, financial, informational, and establishes relationships within them. In this context, it is appropriate to solve the problem of involving the manager into the corresponding flow, for example, as a "social flow manager", "production flow manager", "financial flow manager", "information flow manager" - by analogy with the already established concept of "energy flow manager" or "energy manager."

The latter aspect could be understood as setting goals for management for planning (policies, goals, indicators), coordination (infrastructure, communications, resources, processes, knowledge, changes), internal assessment, improvements (analysis, including risk analysis) of flows.

The ability to solve problems creates a management potential, which includes "a set of principles, methods, tools and forms of production and enterprise management in a market economy with the goal of achieving high efficiency" [19].

Guided by the goals and objectives of the business, the business administration of the enterprise properly organizes the coordination of resources, which are involved into the flows. The appropriate management, interpreted by W. J. Duncan as "coordination of human and other resources with the aim of solving assigned organizational problems" is suitable for the above [4]. It is important for the management to be able to influence the flows by moving the flow to its logical conclusion, i.e. - to the final point. As a result, the enterprise management is filled in with essence and content with the maximum movement to the flows.

\section{Results and discussions}

It is proposed to consider the result of this study as an approach to solving the problem of streamlining an expensive managerial resource in the structure of a modern industrial enterprise.

Rather objectively, such a problem was considered by a group of Russian managers who investigated the structure, factors, and results of activities of the management of enterprises in the coal industry of Russia [10]. An assessment of the current status of activity of enterprise management has shown that more than $50 \%$ of the time is spent on useless work. The work is acknowledged as useless in case, when it does not bring benefits, does not improve the process, when you have to redo something or put in order the process, site, workshop with the additional cost of resources for the implementation of past, outstanding works.

By A. Avilov's behest, the causes of this problem are the following:

- duplication of single responsibility by managers at different levels of the structure, starting with top managers. Top managers duplicate the responsibility of their subordinate managers, and vice versa - managers of a lower level duplicate the responsibility of their leaders;

- lack of knowledge about the operational situation due to distance from the flow, i.e. from the control object. Moreover, the greater the distance, the higher the position the manager occupies. Distance is not offset by the manager's commitment.

- the lack of the ability to apply advanced management methods that provide effective management technologies. The dominant method of work of managers is the meeting and other types of collegial activity [1]. 
The study of the manager's position led us to the conclusion that, within the framework of the existing structure and management approaches, the manager cannot carry out fullfledged effective activity.

Researchers have proposed a number of solutions to this problem related to overcoming the existing state of management activities. Lengnick-Hall proposed to improve the connections and relationships of people in the chain "leader - subordinate" and on this basis the value of their actions should be increased [14].

Dyakova G. believes that the responsibility of the energy manager is to increase the efficiency of energy source use and reduce energy consumption in the energy flow. As a part of improving the energy management system, an algorithm for the development of key indicators has been proposed. The human potential will be measured with those indicators [3].

Using a dynamic model of the potential for innovative development of the enterprise, Bondarenko S. considered the synergetic management, on the basis of which the synergetic effects are managed. Synergetic benchmarking and its effects were proposed as a management tool [2].

Verstina N. confirmed the lack of efficacy of using the total resource potential of the enterprise. The need for the development of integrated resource management tools is identified. The proposed management tools are based on the approaches of "building up" management, which are aimed at the maximum concentration of enterprise resources [16].

Duro H., Sandra L., Dusan L. noted that the concentration of creative resources and clusters are one of the most important forms of the fundamental process of smart enterprises, that strive to achieve sustainable competitive ability. Innovations in production and business processes, including the entire supply chain, during launching both new and improved products and services, are in the focus of attention of heads of intellectual enterprises [5].

Earlier, the author had already considered the topic of concentration of the potential of executives for actions to improve the enterprise management system by introducing the perspective of "management subsystem" [20].

In this study, the author proposed an approach to solving the problem, which consists in eliminating the overlapping responsibilities of managers at the hierarchical levels of the administrative structure. It is possible that such an approach will be accompanied by a transformation of the structure.

It seems that the approach will be implemented through:

- separation of responsibilities of flow managers,

- involvement of the manager in the stream.

By restricting the manager to the objects of his responsibility (materials, information, resources, finances) by the flow framework, the problem of excessive managerial resources will be removed. The manager's activity will become identical to the flow.

For example, in relation to social flows, i.e. to the working with people, it is important for managers to provide sufficient training that will allow them to gain social competence and which will give them the possibility to select confidently the right management tools in the flow of human resources. For such a responsibility of managers, a behaviour matrix (Geiger matrix) could be very useful [8]. The Geiger matrix allows one to determine the level of unity in the relationship of people at four social levels (individual, group, intergroup and system). The use of this tool will allow the manager to get the opportunity of deep involvement in social flows and increase his social competence.

A distinctive feature of the manager's activity will be the presence of a manager's flow by analogy with the availability of labour facilities (machine, model, project, etc.) for a specialist (designer, technologist, economist, etc.), which he directly uses in his work. Moreover, the specialist uses a certain set of professional tools and methods for work performance. From the outside, it looks like working with drawings, diagrams, at a computer, 
with apparatus, etc. [1]. The author's approach involves bringing closer the nature of the manager's work to the nature of work in other professional fields.

Certainly, it is necessary to make a methodological study of the author's approach to the realization of the management potential at the enterprise.

\section{Conclusion}

The activities of a modern manager in an industrial enterprise proceeds under conditions, which are changing rapidly. The high rate of changes in production and in the priorities of owners, risks of a different nature and market factors - they all place increased demands on the personal and professional characteristics of managers, on the set of their competencies, managerial skills and behavioural progress [6].

The author did not set the task of giving the enterprise management new forms of activity that would provide the business administration with confidence in the economic success of their activity.

Nevertheless, a potential has been defined, that includes the managerial aspects of management activities. The management environment has established the flows generated by the enterprise. An approach is proposed for solving the problem of streamlining costly managerial resources in the structure of a modern industrial enterprise.

Thus, the author demonstrated the point of view that the expected economic success could brought closer by the reform of the managerial resource that has historically developed in the administrative structure of the enterprise.

\section{References}

1. Avilov A., Rozmanov O., Sidorov N. A new look at the activities of the leader // Problems of theory and practice of management. 1998. No 3. Pp. 37-48.

2. Bondarenko S. Synergetic Management as a Management Technology of Enterprise Innovative Development // Journal of Applied Management and Investments. 2017. Vol. 6(4). Pp. 223-230.

3. Dyakova G, Izmaylova S., Mottaeva A., Karanina E. Priority directions of the improvement of energy management at the enterprise. IOP Conference Series: Earth and Environmental Science. 2017. Vol. 90. Article number UNSP 012218.

4. Duncan J.W. Great ideas in management. M., 1996.

5. Duro H., Sandra L., Dusan L. Innovation Management in Smart Enterprises // Interdisciplinary Management Research XIII. 2017. Vol. 13. Pp. 280-286.

6. Fridman A. You or Chaos. Professional planning for regular management. M., 2015.

7. Enterprise cash flow: a short classification. URL: http://www.elitarium.ru/denezhnyjpotok-vyruchka-pribyl-realizacija-aktivy-investicii-upravlenie-finansami/ (Date of access: 28.11.2019).

8. Geiger E., Sheppard K. Efficient management prerequisites (Geiger Association, Germany) // Russian Coal Journal. 2008. Special issue SuEK. Pp. 26-28.

9. ISO 9000:2015(en) Quality management systems - Fundamentals and vocabulary. URL: https://www.iso.org/obp/ui/\#iso:std:iso:9000:ed-4:v1:en (Date of access: 28.11.2019).

10. Karpov A.N., Buinitsky A.I., Osharov A.V., Kilin Y.A., Lapaeva O.A. Enterprise Manager performance: activity structure, factors, results assessment criteria // Coal. 2018. No 1 (1102). Pp. 7-12.

11. Kravchenko A.I., Tyurina I.O. Sociology of Management. M., 2008.

12. Kolokolov A. Sankey diagram for flows visualizing. URL: https://alexkolokolov.com/sankey_power_bi (Date of access: 28.11.2019). 
13. Logistics in the management system. URL: http:/www.klubok.net/article2728.html (Date of access: 28.11.2019).

14. Lengnick-Hall C.A., Rigsbee C.M. Strategic Human Resource Management and Supply Chain Orientation // Human Resource Management Review. 2013. Vol. 23. Pp. 366-377.

15. Okrepilov V.V. Glossary of terms and definitions in economics and quality management. M., 1999.

16. Verstina N. Formation of tools of resource providing management at the enterprise of the industry of construction materials in modern conditions // MATEC Web of Conferences. 2017. Vol.106. Article number 08091.

17. Volosskiy A.A. Motivation and stimulation of labour. M., 2007.

18. What is Business Administration?

URL: https://web.archive.org/web/www.ru.nl/businessadministration/about_business/ (Date of access: 28.11.2019).

19. Zakharenko E.N., Komarova L.N., Nechaeva I.V. New dictionary of foreign words. M., 2006.

20. Zotov Fyodor P. Management Subsystem as the Fifth Perspective of the Balanced Scorecard Concept // Upravlenets-the Manager. 2015. Issue 2. Pp. 65-69. 